\title{
Electronic Markets on digitalization
}

\author{
Rainer Alt ${ }^{1}$ \\ (C) Institute of Applied Informatics at University of Leipzig 2018
}

Dear readers,

How often have you come across the saying that "data is the new oil" (e.g. Lahtiranta and Hyrynsalmi 2018)? For sure, data has always been the "fuel" for scientific research, but now data is also regarded as the essential ingredient for businesses and the entire society. These data-driven innovations are the special theme in the present issue and all articles use sets of data to answer their respective research question. While data or facts are indeed the necessary "oil" for researchers and decision-makers alike, their potential for adding value in the marketplace seemed underestimated for a long time. Electronic data processing systems were conceived as efficient "number crunchers", but not necessarily as the sources of competitive advantage. Although first insights regarding the strategic impact of information systems were published during the 1980s (e.g. Porter and Millar 1985), the opinion that information technology (IT) is rather an instrument than an enabler has prevailed in many businesses.

In view of steadily growing IT performance, the possibilities to obtain, to process and to distribute data have increased significantly. With digitalization, practically all types of medial representations - from numbers to pictures, audio and video became digitally available. In consequence, the media industry is known as an impressive example how digitalization has changed industry boundaries (e.g. Alt and Militzer-Horstmann 2017; Hess and Constantiou 2018). However, it was only recently that the notion of digitalization has gained broader attention in the academic and especially in the practitioner's world. For example, in the German speaking countries, the search term "Digitalisierung" (digitalization) has surpassed the word "Wirtschaftsinformatik" (business information systems or business informatics) following Google Trends since the end of 2015. A similar picture may be obtained with English terms, where "digitalization" overtook "information systems" in November 2018. Although these are only simple observations,

Rainer Alt

rainer.alt@uni-leipzig.de

1 Information Systems Institute, Leipzig University, Grimmaische Str. 12, 04109 Leipzig, Germany both queries indicate that the term digitalization was already used prior to the current heydays.

\section{Digitalization 1 - technology}

The early connotation of digitalization is technological in nature and may be traced back to Gottfried Wilhelm Leibniz in the 17th century. He introduced the transformation from arabic numbers to binary strings where "digital" denoted something countable and was derived from the Latin word "digit" for finger (Vogelsang 2010, p. 7). Thus, technological digitalization refers to the process of transferring data from an analog into a digital (or binary) form of representation. Over time, the complexity of data that could be digitalized grew. While digital code, such as the Morse Code allowed only a very limited amount of data to be transmitted via telegraph lines, digitalization meanwhile encompasses all medial representations. This comprised the conversion of analog signals that may be described as continuous functions of accoustic or light waves that develop over time. Since these continuous signals may have an arbitrary number of potential values (Hardy et al. 2002, p. $96 \mathrm{ff}$.), the process of digitalization creates discrete values by using so-called analog-digital converters (ADC). ADCs, such as sensors in digital cameras (socalled charge-coupled devices, CCD or complementary metal oxide semiconductor, CMOS), or microphones in smartphones (conducting so-called pulse code modulation, PCM), create digital formats (e.g. mp3, mp4, jpg) from these continuous functions. In a similar way, digital-analog converters (DAC) transform digital into analog signals, which typically is the case in voice over IP (VOIP) telephony.

A technological view on digitalization opens a large potential for automation. If data is defined as "a value or set of values representing a specific concept or concepts" (FEA 2005), then these values are in binary form and may be processed, communicated as well as interpreted not only by humans, but also by automatic means (ISO 2015). Automation, however, requires this raw data to be organized (formalized). This is the case in datasets where specific attributes add meaning (e.g. whether a number represents a price or an article number, whether the 
pixels in a photo represent a certain product or whether text represents a certain news topic). Such attributes create socalled labeled or tagged data, whereas unlabeled data lacks appropriate explanations (Bramer 2007, p. 4 f.). While many databases (e.g. open databases used in research) contain labeled data, a large number of data in the big data context is unlabeled (e.g. social media feeds) and requires substantial effort to make it accessible for further usage in information systems.

Technologies from the semantic web, data mining as well as machine learning fall within this technological view on digitalization. They help to make data, which is becoming available from a steadily growing number of creation points (e.g. sensors in smart devices and smart products, events and transactions in application systems, postings and reactions on digital platforms), accessible for further purposes. This allows high degrees of automation in the process of filtering and selecting this data for various points of usage. Transferring raw data to meaningful content is also included in the notion of information itself: "Data become 'information' when analyzed and possibly combined with other data in order to extract meaning and to provide context. The meaning of data can vary depending on its context." (FEA 2005). In the literature, hierarchical models, such as the DIKW (data, information, knowledge, wisdom) hierarchy, reflect this higher order of information also combined with the terms knowledge and wisdom. Following this thinking, information is inferred from data and knowledge or know-how is obtained from information. It creates the basis for intelligence and ultimately wisdom. Intelligence is associated with the ability to increase efficiency and wisdom with the ability to increase effectiveness (Rowley 2007, p. 166). In the opposite direction, learning processes that occur on higher levels influence the action on lower levels.

\section{Digitalization 2 - application}

Although the strict and schematic concept of the DIKW hierarchy has provoked a controversial debate, it emphasizes the need for contextualization, which usually occurs through application. Since these application settings may be diverse, this second meaning of digitalization is much broader. It comprises the way of doing things from the perspective of the individual, of one or more organizations as well as of economies and societies as a whole. Along the dimensions mentioned above, on the one hand, improvements are possible within the existing structure and may affect efficiency. On the other, improvements that introduce new structures affect effectiveness. This is why digitalization is closely related to the notions of digital innovation and digital transformation (Matt et al. 2015). The strength of digitalization lies in the possiblity to support both efficiency as well as effectiveness and to combine them with higher user experience. This may be seen in each of the three application perspectives:
- The perspective of the individual captures digitalization occurring in various areas of life, such as work, mobility, health, finance or home. With technological infrastructures, such as videotext systems, personal computers, the internet and, more recently, mobile devices and cloud computing, employees, customers, patients or citizens have received digital support early on and the process of making them an integral part of the respective processes is still ongoing. However, existing digital solutions for individuals are primarily offered by companies, which use them to maximize their own goals. Instead, tools that empower individuals to share data, to obtain transparency and to provide value propositions that reach across multiple providers (e.g. a medical treatment plan with several doctors and medical institutions) may be expected in the future. This development will have to take in to account that in contrast to the typical desire of businesses to collect a maximum of data, individuals treasure data frugality. A contribution for measuring the socalled privacy paradox is included in the present issue.

- The perspective of the organization comprises digitalization within single as well as between multiple enterprises. Especially service companies, such as banks or airlines, were pioneers in adopting IT to digitalize their business functions. Starting in the mid-twentieth century digitalization grew from performing localized computations (e.g. invoicing) to encompass larger functional business tasks (e.g. accounting) up to the entire enterprise (Venkatraman 1994). In the latter phase, integrated internal application systems referred to as enterprise resource planning systems (ERP) created centralized digital platforms within the company and permitted redesigned cross-functional process designs. The more digital resources (e.g. smart machines, digital documents) were involved, the more fully automated processes and the more powerful decision support became possible. A recent example of digital process automation is robotic process automation (RPA) where software ("robots") increase efficiency via automating routine manual activities, for example, extracting data from one system, checking this data against data from another system and finally entering it into a system. Besides digitalizing businesses processes, digitalization has increasingly affected effectiveness and defined the products as well as the business strategies themselves. This comprises the enhancement of physical products with digital components (smart products), the addition of physical products with digital services (product service systems) as well as the virtualization of physical products by means of digital products (digital or smart services). It is the notion of service that leads to data-based business models, which allow personalization, individualization and the shift towards pay-per-use schemes that focus on experiencing value instead of possessing (smart) goods.

- The perspective of society recognizes the role of IT for social and political communication. Various seminal works have 
been authored in this domain (e.g. Hornridge 2011): For example, the computerization of society (Nora and Minc 1981) predicted an information society, which would profoundly change complete areas of the economy. This would include the rise of the IT industry as well as the diffusion of technology in all industry sectors and in the social infrastructure. In 1999, the book trilogy "information age" (Castells 2010) proposed that IT would make networks the dominating form of organization in all sectors of society and that they would shape a new social order. This would lead to effects of disaggregation and reintegration and globalization alike, thereby changing the division of labor, market structures, power relationships and the organization of capital. While networks reduce hierarchical forms of organization, metanetworks would, however, entail a globalization of critical aspects, such as capital and social values, which would then create new power bases. This is well reflected in the influence of today's large digital players (e.g. Alibaba, Amazon, Apple, Facebook, Google, Microsoft, Tencent, Twitter), which increase the efficiency of social interaction, but which also impact markets and industries as well as public and political opinion making. As emphasized by current research (e.g. Bharadwaj et al. 2013), this development is far from over and rather tends to accelerate.

\section{Digitalization and Electronic Markets}

Both views illustrate that instead of being a new phenomenon, digitalization builds on the convergence of developments that have been being discussed separately for some time. In fact, the term "digitalization" or "digitization" was limited to the technological view for a long time and the applied perspective was associated with keywords, such as "strategic information systems", "ERP", "knowledge management", "electronic commerce" or "internet society". Nowadays, digitalization brings both views together and opens a broad field for research and innovation in academia and practice. It may be structured along the five layers of the DIKW hierarchy as mentioned above (Rowley 2007) and the three layers known from business engineering (Österle 1996): strategy, organization and information system (see Fig. 1):

- Technological digitalization creates the basis for digitalization in all areas of application. It is the domain of computer science as well as electrical engineering and aims at capturing and executing data automatically with sensors, actuators and other devices at their points of creation and usage. Data that is in a digital form of representation on digital data carriers leads to large "lakes" or collections of unlabeled data without prior meaning. In addition to improving the technological infrastructure to allow ubiquitous, secure, cross-device, real-time data access and enrichment, questions of who owns data and how unintended uses of (personal) data may be prevented are among topics where promising research is ongoing.

- Applied digitalization starts with contextualizing data, which occurs differently by individuals, in organizations and the society as a whole. Individuals use applications on various devices and more comprehensive functionality allowing to efficiently pursue activities in various areas of their lives, thus improving the "effectiveness of living". Organizations have internal ERP systems in place that implement digital processes and coordinate resources to increase efficiency. Effectiveness would include digital products and business models, such as car sharing, autonomous mobility, media streaming or hospitality services. Finally, on the larger level of society, public open data platforms as well as social media offerings enable networked processes that not only improve the sharing of information and the emergence of knowledge, but which also shift the power bases within the social system.

Electronic Markets has a long tradition in addressing digitalization topics. As a journal from the information systems discipline, it emphasizes the application view and considers digitalization as the design and application of IT-based
Fig. 1 Examples for the impact of digitalization following the knowledge hierarchy
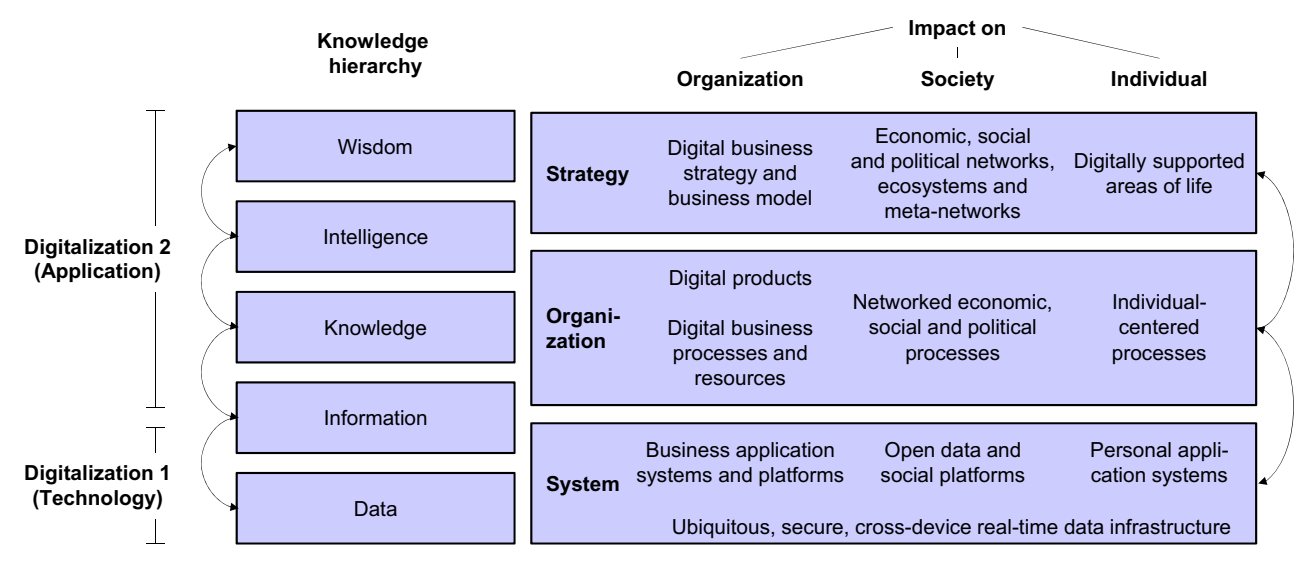
solutions by individuals, organizations and society to increase user experience, efficiency and effectiveness. In fact, this definition comprises all digitalization topics listed by Pagani and Pardo (2017, p. 187), such as "EDI (Electronic Data Interchange) systems; websites; electronic marketplaces; extranets; electronic auctions; MRP (Manufacturing Resource and Planning) systems; ERP systems; RFID (Radio Frequency Identification) Systems; intelligent agent systems; etc.". However, Electronic Markets would expect that technological topics, such as RFID or intelligent agent systems, are discussed together with applications aspects. In addition, the dimensions of the individual and the society are considered as relevant topics. This is reflected in:

- Past special issues. For example, the special issue on "information and data quality in networked business" (Otto et al. 2011) covered digitalization in the organizational dimension, the special issue on "personal data markets" (Spiekermann et al. 2015) was largely centered around data of individuals and the special issue on "big data analytics" (Ngai et al. 2017) included research in the organization and social dimension.

- Upcoming special issues. Two separately scheduled special issues are closely related to digitalization. A special issue for volume 29 is currently in preparation and will target the "digitization of the individual". Another special issue call has been created for Electronic Markets' 30th volume and aims to advance the understanding of the past as well as the future impact of digitalization on a broader scale.

In summary, it has been argued that digital data may be considered as a raw material that when put into context has the power to transform organizations, societies and the world of the individual. Groundwork already exists and convergence may be expected to act as a driver for future developments. An analogy may be found in the organizational dimension where only the availability of integrated intra-organizational (ERP) systems made internal cross-functional processes possible. In a similar way, the availability of an inter-organizational digital infrastructure paves the way for more efficient and for redesigned digital processes as well as business models (Alt and Zimmermann 2015). Two recent examples may illustrate the expectations associated with such data-based models: First, in 2018 Amazon not only passed the billion-dollar market capitalization with their data-based e-commerce business and their digital web services, but also reported the strongest revenue growth (130\%) in their Q3 financial results from selling data, i.e. banners and ads (Creswell 2018). Second, it was reported that the data-based ride-hailing company Uber could be valued at 120 bn. USD in a possible IPO expected for 2019. This would be "more than General Motors Co., Ford Motor Co. and Fiat Chrysler Automobiles NV are worth combined" (Hoffman et al. 2018).

\section{Articles of present issue}

The special theme of this issue contributes to the understanding of data-driven business innovations and business models. The four articles have emerged from conference papers that were presented at the International Conference on Wirtschaftsinformatik (WI 2017) in St.Gallen, Switzerland. All papers will be introduced in the preface by the guest editors Barbara Dinter from the University of Chemnitz, Germany, and Jan Krämer from the University of Passau, Germany (Dinter and Krämer 2018). They have managed the process from selecting the conference papers to organizing the review process and have put an exciting set of papers together. These are followed by four general research contributions, which all feature an empirical research design that uses sets of quantitative data to answer their respective research questions.

- The first paper seamlessly continues the special theme. Authored by Henner Gimpel, Dominikus Kleindienst and Daniela Waldmann, "The disclosure of private data" aims to measure the privacy paradox in digital services (Gimpel et al. 2018). This paradox links to the data frugality that was mentioned above and argues that although data privacy is a desire, consumers have difficulty in measuring the value of their data and often disclose personal data despite the associated risks. Using design science, the authors suggest a privacy paradox metric that helps consumers and businesses assess the consequences of their data privacy decisions.

- The second paper is titled "Bid more, pay less" and discusses the phenomenon of overbidding in electronic auctions, which has been referred to as "bidder's curse". It denotes the observation that in their desire to purchase a certain good, buyers tend to pay more than the fixed price. Based on a large dataset of recorded bids in Dutch auctions, Fabian Ocker found that offline bidders experienced overbidding more often than online bidders and that learning effects were absent, even for active customers (Ocker 2018).

- The third paper poses the question "Name it as you like it?", which picks up the observation that terminology in the IT domain is fast changing. Using the example of social media, Julian Bühler and Markus Bick, investigate the use of terminology based on an analysis of scholarly papers that were published between 2005 and 2017. They confirm an imprecise usage, where different terms are used interchangeably and propose a taxonomy of five semantic clusters that add to a more stable and precise use of terminology (Bühler and Bick 2018).

- The fourth paper analyzes the "Dynamics of investor communication in equity crowdfunding" and connects to Electronic Markets' last special issue (Alt et al. 2018). In the preface, crowdfunding was included as one important field of FinTech where digital platforms allow individuals to invest in start-up businesses. The authors, Gregor 
Dorfleitner, Lars Hornuf and Martina Weber pursue the question, whether start-ups update the data published regarding their business on the crowdfunding platforms. Their findings indicate that data is neither always up-to-date nor complete and that under certain circumstances stricter investor communications should take place (Dorfleitner et al. 2018).

The editorial team of Electronic Markets wishes to thank all authors and reviewers as well as guest editors and editors who were involved in the articles for this issue. We hope that you are also satisfied with the outcome and again are impressed by the commitment of all. This is also reflected in the positive feedback that we received after the invitations for new members that were decided at the last editorial board meeting. We welcome Katharina Ebner from Fernuniversität in Hagen, Germany, Sohail Chaudry from Villanova University, USA and Christian Matt from the University of Bern, Switzerland, as new members of the editorial board. We are also honored that Mathias Klier from the University of Ulm, Germany, has accepted our invitation as associate editor and that Andreja Pucihar from the University of Maribor, Slovenia, as well as Marianna Sigala from the University of South Australia, have joined the team of senior editors. Our gratitude also goes to Ronald M. Lee from Florida International University, who has been an editorial board member since 1999 and has now decided to step down from the board. Professor Lee was the author of two articles in Electronic Markets and has reviewed several submissions. We would like to thank him for his contribution and longterm support of Electronic Markets.

Finally, the editorial board has approved a new section in Electronic Markets. It connects to the observations by Bühler and Bick that a solid terminology is necessary especially in dynamic fields of knowledge. For this purpose, the section "Fundamentals" gives room to shorter papers that serve to structure recent topics of interest in the field of electronic markets and networked business. Articles in this section should offer an understanding of the topic's relevance, its main characteristics, a definition, examples as well as an outlook. In contrast to research papers, papers submitted to the "Fundamentals" section should primarily structure existing knowledge and offer guidance, e.g. by proposing a framework based on existing research. If you have ideas on possible Fundamentals topics or feedback to this or other sections, please do not hesitate to let us know.

Your EM-team

\section{References}

Alt, R., \& Militzer-Horstmann, C. (2017). Electronic Markets on the media industry. Electronic Markets, 27(1), 1-5. https://doi.org/10. 1007/s12525-017-0246-5.
Alt, R., \& Zimmermann, H.-D. (2015). Editorial 25/3: Electronic Markets on ecosystems and tourism. Electronic Markets, 25(3), 169-174. https://doi.org/10.1007/s12525-015-0197-7 .

Alt, R., Beck, R., \& Smits, M. T. (2018). FinTech and the transformation of the financial industry. Electronic Markets, 28(3), 235-243. https://doi.org/10.1007/s12525-018-0310-9.

Bharadwaj, A., El Sawy, O. A., Pavlou, P. A., \& Venkatraman, N. (2013). Digital business strategy: Toward a next generation of insights. MIS Quarterly, 37(2), 471-482.

Bramer, M. (2007). Principles of data mining. London: Springer.

Bühler, J., \& Bick, M. (2018). Name it as you like it? Keeping pace with social media something. Electronic Markets, 28(4). https://doi.org/ 10.1007/s12525-018-0306-5.

Castells, M. (2010). The rise of the network society (2nd ed.). Chichester: Wiley-Blackwell.

Creswell, J. (2018). Amazon sets its sights on the $\$ 88$ billion online ad market. The New York Times, (Sept. 3) https://www.nytimes.com/ 2018/09/03/business/media/amazon-digital-ads.html, accessed, Nov. 02, 2018.

Dinter, B., \& Krämer, J. (2018). Data-driven innovations in electronic markets. Electronic Markets, 28(4). https://doi.org/10.1007/ s12525-018-0316-3.

Dorfleitner, G., Hornuf, L., \& Weber, M. (2018). Dynamics of investor communication in equity crowdfunding. Electronic Markets, 28(4). https://doi.org/10.1007/s12525-018-0294-5.

FEA (2005). The data reference model, version 2.0. Federal enterprise architecture program, November 17. http://xml.coverpages.org/ FEA-DRMv20Final-2005.pdf, accessed, Nov. 01, 2018.

Gimpel, H., Kleindienst, D., \& Waldmann, D. (2018). The disclosure of private data: Measuring the privacy paradox in digital services. Electronic Markets, 28(4). https://doi.org/10.1007/s12525-0180303-8.

Hardy, D., Malleus, G., \& Mereur, J.-N. (2002). Networks - Internet, telephony, multimedia. Berlin/Heidelberg: Springer. https://doi.org/ 10.1007/978-3-642-55498-8.

Hess, T., \& Constantiou, I. (2018). Introduction to the special issue on "Digitalization and the Media Industry". Electronic Markets, 28(1), 77-78. https://doi.org/10.1007/s12525-017-0282-1.

Hoffman, L., Bensinger, G., \& Farrell, M. (2018). Uber proposals value company at $\$ 120$ billion in a possible IPO. Wall Street Journal (Online), October 16, https://www.wsj.com/articles/uber-proposalsvalue-company-at-120-billion-in-a-possible-ipo-1539690343, accessed Oct. 20, 2018.

Hornridge, A.-K. (2011). 'Knowledge society' as academic concept and stage of development - A conceptual and historical review. In T. Menkhoff, H.-D. Evers, \& E. F. Pang (Eds.), Beyond the knowledge trap (pp. 87-127). Singapore: World Scientific. https://doi.org/10. 1142/9789814343688_0004.

ISO (2015). Information technology - vocabulary. ISO/IEC 2382: 2015(en). International Organization for Standardization. https:// www.iso.org/obp/ui/\#iso:std:iso-iec:2382:ed-1:v1:en, accessed Nov. 1, 2018.

Lahtiranta, J., \& Hyrynsalmi, S. (2018). Crude and rude? Old ways in the new oil business. Communications of the ACM, 61(11), 34-35. https://doi.org/10.1145/3195179.

Matt, C., Hess, T., \& Benlian, A. (2015). Digital transformation strategies. Business Information Systems \& Engineering, 57(5), 339-343. https://doi.org/10.1007/s12599-015-0401-5.

Ngai, E. W. T., Gunasekaran, A., Wamba, S. F., Akter, S., \& Dubey, R. (2017). Big data analytics in electronic markets. Electronic Markets, 27(3), 243-245. https://doi.org/10.1007/s12525-017-0261-6.

Nora, S., \& Minc, A. (1981). The computerization of society: A report to the President of France. Cambridge (MA): MIT Press.

Ocker, F. (2018). "Bid more, pay less" - Overbidding and the bidder's curse in teleshopping auctions. Electronic Markets, 28(4). https:// doi.org/10.1007/s12525-018-0295-4. 
Österle, H. (1996). Business in the information age. Berlin etc: Springer.

Otto, B., Lee, Y. W., \& Caballero, I. (2011). Information and data quality in networked business. Electronic Markets, 21(2), 79-81. https:// doi.org/10.1007/s12525-011-0062-2.

Pagani, M., \& Pardo, C. (2017). The impact of digital technology on relationships in a business network. Industrial Marketing Management, 67, 185-192. https://doi.org/10.1016/j.indmarman. 2017.08.009.

Porter, M. E., \& Millar, V. E. (1985). How information gives you competitive advantage. Harvard Business Review, 63(4), 149-160.

Rowley, J. (2007). The wisdom hierarchy: Representations of the DIKW hierarchy. Journal of Information Science, 33(2), 163-180. https:// doi.org/10.1177/0165551506070706.
Spiekermann, S., Acquisti, A., Böhme, R., \& Hui, K.-L. (2015). The challenges of personal data markets and privacy. Electronic Markets, 25(2), 161-167. https://doi.org/10.1007/s12525-0150191-0.

Venkatraman, N. (1994). IT-enabled business transformation: From automation to business scope redefinition. Sloan Management Review, 35(2), 73-87.

Vogelsang, M. (2010). Digitalization in open economies. Berlin/ Heidelberg: Springer. https://doi.org/10.1007/978-3-7908-2392-9. 